\title{
The association between wing morphology and dispersal is sex-specific in the glanville fritillary butterfly Melitaea cinxia (Lepidoptera: Nymphalidae)
}

\author{
CAsper J. BREUKER ${ }^{1}$, Paul M. BRAKEFIELD ${ }^{2}$ and Melanie GIBBS $^{3}$ \\ ${ }^{1}$ Centre for Ecology and Conservation, University of Exeter, Cornwall Campus, Penryn, TR10 9EZ, UK; \\ e-mail: casper_j_breuker@yahoo.co.uk \\ ${ }^{2}$ Department of Evolutionary Biology, Institute of Biology, Leiden University, P.O. Box 9516, \\ 2300 RA Leiden, The Netherlands \\ ${ }^{3}$ Biodiversity Research Centre, Ecology and Biogeography Unit, Catholic University of Louvain, (UCL), Croix du Sud 4, \\ 1348 Louvain-la-Neuve, Belgium
}

Key words. Lepidoptera, Nymphalidae, glanville fritillary, Melitaea cinxia, dispersal, wing shape, body morphology, individual quality, fluctuating asymmetry, wing aspect ratio, wing loading, sexual dimorphism

\begin{abstract}
We examined whether dispersal was associated with body and wing morphology and individual quality, and whether such an association was sex-specific, in the Glanville fritillary butterfly Melitaea cinxia (L.) in Paldiski on the north coast of Estonia. Body weight, size and shape of both fore- and hindwing, wing aspect ratio and wing loading were used as measures of body and wing morphology. Fluctuating asymmetry (FA) of wing shape was used as a measure of individual quality. Males and females did not differ in dispersal rates, despite large differences in overall morphology and FA. Females had a significantly higher wing loading and aspect ratio, but a lower FA than males. Females, but not males, that dispersed differed in forewing shape from those that did not disperse. The sex-specifity of the covariation between dispersal and forewing shape is most probably due to wing shape being associated with different life-history traits in both sexes, resulting in different selection pressures on wing shape in each of the sexes.
\end{abstract}

\section{INTRODUCTION}

Dispersal in butterflies has often been regarded as an adaptation to spatial and temporal heterogeneity in habitat quality (see for review Singer \& Hanski, 2004). The question remains, however, which factors exactly affect or drive dispersal? In general, dispersal in butterflies is very much associated with the availability of both suitable oviposition sites and/or mates. These two factors depend largely on population density (Baguette \& Neve, 1994; Baguette et al., 1996), degree of habitat fragmentation, host plant preference, quality and abundance (Saccheri et al., 1998; Hanski, 1999; Van Nouhuys \& Hanski, 1999; Hanski \& Ovaskainen, 2000; Kuussaari et al., 2000; Hanski et al., 2000, 2002), the time available for oviposition, as well as the size and number of eggs that females lay on individual host plants (Nylin \& Janz, 1996; Kuussaari et al., 2000; Nylin et al., 2000; Hanski et al., 2002; Singer \& Hanski, 2004; Gibbs et al., 2005). Furthermore, variation in dispersal is often sex-specific with males and females having different life-history strategies associated with flight and dispersal, while both sexes are often also being differently affected by environmental variation (Van Dyck \& Wiklund, 2002; Gibbs \& Breuker, 2006). Females are usually the more dispersive of the two sexes as they need to fly around, often for extended periods of time, to find suitable oviposition sites or to avoid harassment by males (Baguette \& Neve, 1994; Baguette et al., 1996; Gibbs et al., 2004, 2005).

In order to establish the relative importance of each factor associated with dispersal, careful experimental design is required, where some factors are held constant whilst others are being varied. A study system where many such studies have been undertaken is the Finnish network of metapopulations of the Glanville fritillary butterfly Melitaea cinxia (L.) (Hanski et al., 2002, 2004). In 1999, a mark-release-recapture study was performed in which the dispersal of marked $M$. cinxia butterflies was monitored among habitat patches on the Åland islands in the south-west of Finland. The butterflies used in this study had been collected as larvae from several local populations of a large network of metapopulations on the Alland Islands and from one large local population in Paldiski on the north coast of Estonia. These larvae were reared in the laboratory and subsequently released after eclosion (Hanski et al., 2002, 2004). It was found that the factors associated with dispersal affected both sexes differently. Females, but not males, from newly established populations were more dispersive. Furthermore Paldiski females, which had their preferred host plant missing from the release site and surrounding area, showed the highest emigration rates and were found to be more dispersive relative to females from the Åland populations. However, within a local population, population history (i.e. old versus newly established population) and preferred host plant availability are not able to explain the variation in dispersal amongst individuals. For example, although females from Paldiski were on average more dispersive, not all Paldiski females dispersed. Individual quality and body morphology are two factors that may well explain this variation in dispersal amongst individuals within a local population. A study on M. cinxia on 
the Baltic island of Öland indicated that variation in overall body morphology was associated with variation in habitat fragmentation and dispersal, and that males and females have adapted differently to habitat fragmentation (Norberg \& Leimar, 2002). In birds, it has been suggested that variation in individual quality may cause variation in dispersal rates (e.g. Rintamaki et al., 1995; Matessi, 1997).

Developmental stability has been proposed as a measure of individual quality (Moller, 1997; but see Clarke, 2003). Developmental stability refers to a suite of processes aimed at buffering random perturbations during development (i.e., developmental noise). Under stressful conditions it becomes increasingly difficult to buffer developmental noise because energy and resources are being diverted away from growth into the stress response (Swaddle \& Witter, 1994; Buchanan, 2000; Hovorka \& Robertson, 2000). The joint action of developmental noise and developmental stability results in a certain amount of developmental imprecision or developmental instability, of which fluctuating asymmetry (FA) is a measure (Van Valen, 1962; Markow, 1995). Fluctuating asymmetry refers to random asymmetries of bilaterally symmetrical traits, with differences between left and right being normally distributed with a mean of zero (Palmer \& Strobeck, 1986, 2003). A decrease in developmental stability is hypothesized to be associated with a decrease in fitness and individual quality (e.g. Moller, 1997).

Asymmetries in wing length and/or wing shape may also negatively interfere with flight ability, as has been reported for birds (e.g. Swaddle, 1997). It is not clear, however, whether this also applies to insects as it appears that there usually is a significant directional asymmetry (DA) for wing shape (Windig \& Nylin, 1999; Mardia et al., 2000; Klingenberg et al., 2001), which may even be adaptive (Windig \& Nylin, 1999). Dispersal might hence not only covary with wing morphology, but also with the asymmetry of wing morphology.

In our study, using individuals from the Paldiski local population, we investigated whether dispersal was associated with morphology and individual quality. Given the sex-specifity of factors affecting dispersal in M. cinxia, we furthermore investigated whether such associations were sex-specific. As measures of morphology we used body weight, size and shape of fore- and hindwings, and wing loading. The asymmetry (FA) of wing shape was used as a measure of individual quality.

\section{MATERIAL AND METHODS}

\section{Experimental animals}

Larvae were collected at random in the wild in spring 1999 from a large, outbred, local, and isolated population of butterflies in Paldiski, on the north coast of Estonia. The larvae were at the final or penultimate stage of development. All larvae were then reared in a common environment. Rearing details are given by Hanski et al. (2002).

\section{Obtaining data prior to release in the field}

The butterflies were transferred a few hours after emergence (i.e. when their wings were fully hardened and dried) to a cool room at $\pm 5^{\circ} \mathrm{C}$ for about $10 \mathrm{~min}$ in order to slow down their activity. This facilitated processing which consisted of three steps: (i) photographing, (ii) weighing (accuracy $1 \mathrm{mg}$ ), and (iii) numbering. This procedure had no long-lasting effects on activity.

Photographs were taken with a Nikon F801S (180 mm Sigma macro) under standard conditions of light and position of the butterfly with respect to camera. Photographs were taken twice for each individual in order to obtain an accurate unbiased estimate of measurement error. All films were from the same batch from Fuji. An 18\% grid gray card in the same plane alongside the butterfly was photographed to ensure consistent film development. Images were then digitized in a random sequence with respect to source population and order of photography.

\section{Release and recapture}

The animals were released near the centre of the small village Löfö (island of Vårdö, Åland) on either a large (release patch 1, $0.35 \mathrm{ha}$ ) or small meadow (release patch 2, 0.08 ha). The released butterflies were divided on each release occasion roughly in the ratio $2.5: 1$ amongst the two release patches to standardize butterfly density. The release of the butterflies on the two patches was random with respect to sex. The butterflies were recaptured daily by surveying the two release patches and the surrounding small roads with flower-rich roadsides, with equal recording effort per unit area (i.e. time spent recording butterflies per unit area was the same). Dispersal is a binary variable $(0 / 1)$. A " 0 " corresponded to no dispersal. These animals stayed in the release patch and were never recorded outside the release patch. A "1" corresponded to dispersal. These animals were recorded outside the release patch (after Hanski et al., 2002). Butterflies that dispersed tended to leave the release patch immediately (i.e. within $24 \mathrm{~h}$ ) and tended to fly long distances (i.e. to places up to $3 \mathrm{~km}$ away from the release patch) (pers. obs.). These binary values correspond to the two extremes of another measure of dispersal, i.e. dispersal propensity, detailed in Hanski et al. (2004).

\section{Measurements}

The order of measurements was random with respect to photography, scanning and source population. Measurements of wing shape were carried out on 258 animals using SCION IMAGE (freeware from NIH, USA, 1998). Repeatability and accuracy of the measurements and position on the wing were used as criteria in selecting landmarks (see Fig. 1 for position of all 8 landmarks on the wings, with landmark 1 being a landmark for both fore- and hindwing). Landmarks were used to determine the fore- and hindwing (FW and HW) size and shape. Each butterfly was photographed twice, and for each photo we digitized all 8 landmarks twice in order to assess measurement error. Repeatabilities of the measurements (i.e. positions of landmarks) were high. Using regression analyses between repeated measurements we assessed that accuracy was between $98 \%$ and $99.5 \%$

The coordinates of the landmarks can be used to calculate the centroid size. This is the square root of the sum of squared distances from a set of landmarks to their centroid (references and details in Klingenberg \& McIntyre, 1998). Centroid size was calculated separately for both FW and HW. In this study, centroid size was used as a measure of wing size (cf. Klingenberg et al., 2001). We calculated the following two measures of flight performance and wing shape: (1) Wing aspect ratio (FW length ${ }^{2}$ / FW wing area), and (2) wing loading (total body weight / total wing area) (cf. Betts \& Wootton, 1988). Wing aspect ratio is a popular measure of the slenderness of a wing (a high wing aspect ratio corresponds to slender wings), and as such gives an overall description of the shape of the wing (cf. Wickman, 


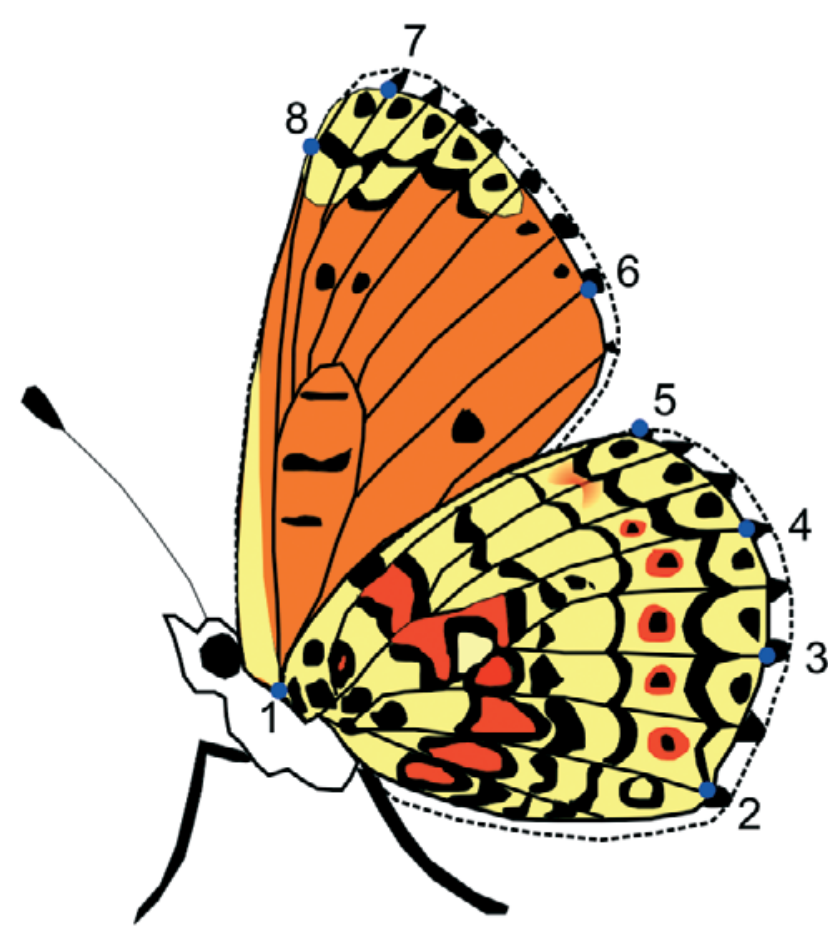

Fig. 1. The 8 landmarks measured for Melitaea cinxia butterflies. Note that the first landmark (nr 1) is a shared landmark between the forewing (FW) and hindwing (HW).

1992). To investigate in more detail the subtle differences in shape and asymmetry of shape in a wing, we also performed geometric morphometrics on the landmark configurations.

\section{Statistical analyses}

Variation in shape was examined by using geometric morphometrics based on generalized least squares Procrustes superimposition methods (Goodall, 1991; Dryden \& Mardia, 1998; Klingenberg \& McIntyre, 1998). These morphometric and all other analyses were carried out in R (http://cran.r-project.org), and in particular using the statistical package shapes written by I.L. Dryden for use in R (based on methods described in Dryden \& Mardia, 1998). Furthermore, to compare differences in shape between groups we used the IMP (Integrated Morphometrics Package) program TwoGroup written in Matlab (Mathworks, 2000) by H.D. Sheets (details on use in Zelditch et al., 2004). It is freely available through $\mathrm{http}: / / \mathrm{www} 2$. canisius.edu/ sheets/ morphsoft.html.

Procrustes methods analyze shape by superimposing configurations of landmarks of two or more individuals to achieve an overall best fit. It involves four steps, which have been described in mathematical and descriptive detail elsewhere (see e.g. Klingenberg \& McIntyre, 1998): (1) reflection of either left or right configurations, so that left and right are orientated the same way, (2) scaling to unit centroid size (to remove size and shape associations), (3) superimposing the centroids of all configurations, and finally (4) rotation of the configurations around their centroid to obtain the optimal alignment.

The square root of the sum of the squared distances between corresponding landmarks of two optimally aligned configurations (for example a left and a right wing) is an approximation of Procrustes Distance. We used this Procrustes distance as a measure of individual shape FA. Because there are no negative values, this distance is somewhat similar to size-scaled unsigned individual asymmetry for linear measurements (Breuker \& Brakefield, 2003). For both males and females we therefore used $\log$ transformations of the form [ $\log$ (Procrustes distance) + 5.0] to achieve normality for use in standard parametric statistical tests.

In order to analyse subtle shape differences between groups of individuals, we first calculated the average fore- and hindwing shape for each individual (Procrustes coordinates of each landmark were averaged across both sides and measurements). If a fixed factor needed to be taken into account as a covariate, residual wing shapes were used and were calculated as follows: $X_{i j}$, residual $=X_{i j}-\left(X_{j}-X_{\text {overallmean }}\right)$ (with $X_{i j}$ the shape vector for individual $i$ and factor level $j, X_{j}$ the average shape for factor level $j$, and $X_{\text {overallmean }}$ the overall mean shape of all individuals). Shape differences between groups of individuals were then tested with a bootstrapped version of Goodall's F-test, using 4900 bootstraps. This test makes no assumptions about the distribution of variation around the means of shape that are being compared. We tested for wing shape differences in both fore- and hindwing between dispersing and non-dispersing individuals within each sex.

Differences in morphology and FA between individuals that did and did not disperse were analysed by means of an ANOVA for the following variables: (centroid) size of fore- and hindwings, body weight, wing loading and wing aspect ratio. To investigate which of the variables explained most variation in dispersal we performed logistic regression analyses for the binary variable dispersal with the following variables: size and asymmetry of fore- and hindwings, body weight, wing aspect ratio and wing loading.

Butterflies that developed faster eclosed earlier and were therefore released earlier in this study. Hanski et al. (2002) have shown that butterflies that had been released earlier also had more time to be recorded outside the release patch, hence, to have "dispersed" in our mark-release-recapture study set-up. Release date therefore explained a significant proportion of the variation in dispersal among individuals. Furthermore, variation in development time, hence release date, may be correlated with variation in morphology. For these two reasons release date was used as a covariate in all subsequent analyses.

\section{RESULTS}

Males were morphologically different from females. Not only were their wings smaller and did they weigh less, but they also had a significantly lower wing loading (Table 1, section C). Male $M$. cinxia forewings were less slender than female wings (Table 1, section $\mathrm{C}$ : wing aspect ratio), and taking individual landmarks into account both male fore- and hindwings were overall significantly differently shaped from female wings (Table 2 ). Interestingly, males were also observed to have higher wing shape asymmetries (Table 1, section C). In the field, male $M$. cinxia butterflies generally have a shorter postdiapause larval development time and emerge two to three days before females (Ehrlich \& Hanski, 2004). Males eclosed on average a day earlier than females in this study and were generally released earlier (malefemale comparison for release date, Kruskal-Wallis: $\mathrm{H}=$ $28.56, \mathrm{df}=1, \mathrm{p}<<0.001)$. Although males may appear to have dispersed more than females (males: 44 out of 152 ; females: 22 out of 126), this was not significant after taking release date into account (Table 3a). Therefore, despite significant differences in morphology and different life-history strategies, females were not found to be more dispersive than males. 
TABLE 1. Differences in wing size, wing shape asymmetry, body weight, wing loading and wing shape between individuals that dispersed and did not disperse, and between males and females (FW = forewing, $\mathrm{HW}=$ hindwing). For each trait the mean \pm standard error is given. Shape asymmetry was measured as Procrustes distance between left and right wings. ANOVA-results are given (Fand p-value, with appropriate degrees of freedom), testing for differences between (1) individuals that disperse and do not disperse (disp) within each sex (sections A and B), and (2) males and females (sex) (section C). Release date was used as a covariate $\left({ }^{*}, \mathrm{p}<\right.$ $0.05 ; * *, \mathrm{p}<0.01 ; * * *, \mathrm{p}<0.001)$.

\begin{tabular}{|c|c|c|c|c|c|c|c|c|}
\hline & $\mathrm{N}$ & $\begin{array}{l}\mathrm{FW} \\
\text { size }\end{array}$ & $\begin{array}{l}\text { HW } \\
\text { size }\end{array}$ & $\begin{array}{c}\text { Shape asymm. } \\
\text { FW }\end{array}$ & $\begin{array}{c}\text { Shape asymm. } \\
\text { HW }\end{array}$ & Weight & Wing loading & $\begin{array}{l}\text { FW aspect } \\
\text { ratio }\end{array}$ \\
\hline $\begin{array}{l}\text { Females } \\
\text { nondisp }\end{array}$ & 104 & $16.195 \pm 0.071$ & $15.118 \pm 0.067$ & $0.021 \pm 0.001$ & $0.032 \pm 0.002$ & $127.09 \pm 1.72$ & $4.055 \pm 0.049$ & $17.274 \pm 0.084$ \\
\hline $\begin{array}{l}\text { Females } \\
\text { disp }\end{array}$ & 22 & $16.183 \pm 0.148$ & $15.054 \pm 0.156$ & $0.025 \pm 0.005$ & $0.036 \pm 0.004$ & $131.50 \pm 2.38$ & $4.211 \pm 0.070$ & $17.050 \pm 0.159$ \\
\hline \multicolumn{9}{|l|}{ A } \\
\hline \multirow[t]{2}{*}{$\mathrm{F}_{(1,123)}$ reldate } & & 0.02 & 0.15 & 0.34 & 6.73 & 16.27 & 22.20 & 1.28 \\
\hline & & $\mathrm{p}=0.888$ & $\mathrm{p}=0.697$ & $\mathrm{p}=0.560$ & $\mathrm{p}=0.011(*)$ & $\mathrm{p}=0.000(* * *)$ & $\mathrm{p}=0.000(* * *)$ & $\mathrm{p}=0.260$ \\
\hline \multirow[t]{2}{*}{$\mathrm{F}_{(1,123)} \mathrm{disp}$} & & 0.01 & 0.08 & 1.82 & 0.08 & 0.02 & 0.09 & 0.68 \\
\hline & & $\mathrm{p}=0.919$ & $\mathrm{p}=0.774$ & $\mathrm{p}=0.180$ & $\mathrm{p}=0.773$ & $\mathrm{p}=0.877$ & $\mathrm{p}=0.764$ & $\mathrm{p}=0.413$ \\
\hline $\begin{array}{l}\text { Males } \\
\text { nondisp }\end{array}$ & 107 & $14.538 \pm 0.058$ & $13.034 \pm 0.058$ & $0.029 \pm 0.002$ & $0.037 \pm 0.002$ & $86.29 \pm 1.68$ & $3.159 \pm 0.061$ & $14.646 \pm 0.070$ \\
\hline Males disp & 44 & $14.506 \pm 0.087$ & $13.082 \pm 0.088$ & $0.026 \pm 0.003$ & $0.039 \pm 0.004$ & $89.27 \pm 2.56$ & $3.259 \pm 0.102$ & $14.704 \pm 0.108$ \\
\hline \multicolumn{9}{|l|}{ B } \\
\hline \multirow[t]{2}{*}{$\mathrm{F}_{(1,148)}$ reldate } & & 0.23 & 1.94 & 0.10 & 0.75 & 65.38 & 82.24 & 0.52 \\
\hline & & $\mathrm{p}=0.633$ & $\mathrm{p}=0.166$ & $\mathrm{p}=0.750$ & $\mathrm{p}=0.388$ & $\mathrm{p}=0.000(* * *)$ & $\mathrm{p}=0.000(* * *)$ & $\mathrm{p}=0.473$ \\
\hline \multirow[t]{2}{*}{$\mathrm{F}_{(1,148)} \mathrm{disp}$} & & 0.05 & 0.38 & 0.76 & 0.68 & 0.03 & 0.02 & 0.29 \\
\hline & & $\mathrm{p}=0.815$ & $\mathrm{p}=0.538$ & $\mathrm{p}=0.385$ & $\mathrm{p}=0.410$ & $\mathrm{p}=0.869$ & $\mathrm{p}=0.890$ & $\mathrm{p}=0.594$ \\
\hline \multicolumn{9}{|l|}{$\mathrm{C}$} \\
\hline \multirow[t]{2}{*}{$\mathrm{F}_{(1,274)}$ reldate } & & 0.07 & 1.60 & 0.23 & 1.15 & 76.70 & 102.76 & 2.10 \\
\hline & & $\mathrm{p}=0.796$ & $p=0.206$ & $p=0.636$ & $\mathrm{p}=0.285$ & $\mathrm{p}=0.000(* * *)$ & $\mathrm{p}=0.000(* * *)$ & $\mathrm{p}=0.148$ \\
\hline \multirow[t]{2}{*}{$F_{(1,274)} \operatorname{sex}$} & & 398.60 & 629.58 & 8.29 & 3.05 & 579.08 & 347.98 & 658.96 \\
\hline & & $\mathrm{P}=0.000(* * *)$ & $\mathrm{p}=0.000(* * *)$ & $\mathrm{p}=0.004(* *)$ & $\mathrm{p}=0.082$ & $\mathrm{p}=0.000(* * *)$ & $\mathrm{p}=0.000(* * *)$ & $\mathrm{p}=0.000(* * *)$ \\
\hline
\end{tabular}

In both males and females release date explained a significant part of the variation in weight at emergence and wing loading, but not in wing size, nor in wing shape (Table 1, sections A, B, and C; Table 2). For both sexes both weight and wing loading were negatively correlated

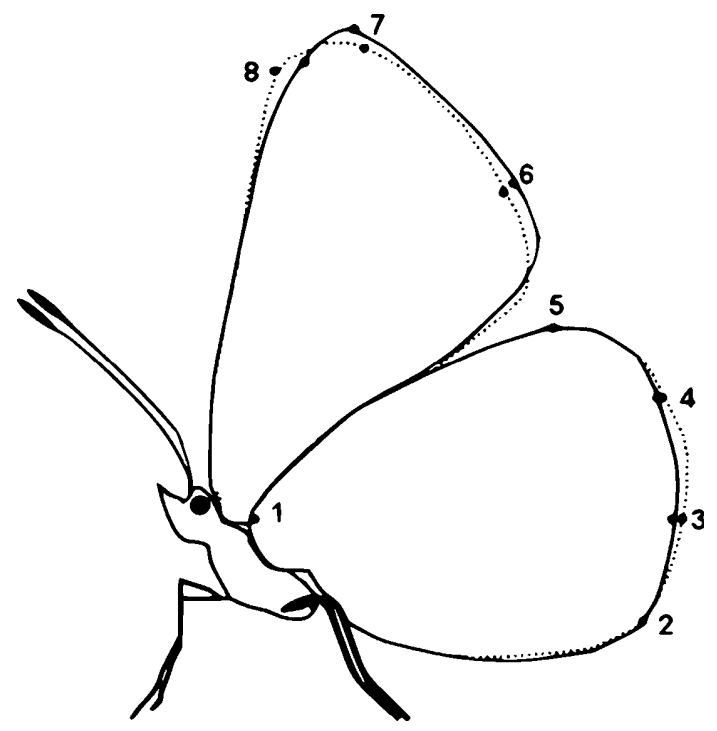

Fig. 2. Wing shapes of female Melitaea cinxia butterflies that dispersed (wing outline dashed), and did not disperse (wing outline solid). with release date (4 regression analyses, $\mathrm{R}^{2}$ range: $12.5 \%-19.8 \%$, all $\mathrm{p}$-values $<<0.001)$. The heaviest, but not necessarily the largest, butterflies and therefore those with the highest wing loading thus eclosed first and were released first. Shape of both fore- and hindwing, however, was not associated with release date. This was established using both wing aspect ratio (Table 1, sections $\mathrm{A}$ and $\mathrm{B})$, and the position of the landmarks with the bootstrapped version of Goodall's F-test (Zelditch et al., 2004) to compare the wing shape of individuals released on one particular day with the wing shape of individuals released on every other day (data not presented, all p-values $>>0.05$; see also Table 2 , comparing shape differences between groups with and without release date as a covariate). Interestingly, the more asymmetrically shaped females (for hind wing) were also released first (Table 1 , section $\mathrm{A}$; regression analysis, $\mathrm{R}^{2}=6.3 \%, \mathrm{p}=$ 0.006).

Using logistic regression models with release date as a covariate, none of the following morphological variables significantly improved the model in both males and females: size, shape (wing aspect ratio) and asymmetry of shape of fore- and hindwings, weight, and wing loading, nor any of the possible interaction terms between release date and these variables. As an example, we have given the logistic regression results for females in Table $3 \mathrm{~b}$ with 
TABLE 2. Comparison of both fore- and hind wing shape between different groups of individuals: males and females, and dispersers from non-dispersers (per sex). Comparisons were performed without (A) and with (B) release date as a covariate. Results presented are from a bootstrapped Goodall's F-test, with 4900 bootstraps: F-value (degrees of freedom between brackets), p-value, Procrustes Distance between shape means (D), SE of distance between Procrustes shape means (SE), and 95\% confidence interval (95\% c.i.) of the bootstrapped estimate of the Procrustes Distance between shape means. FW = forewing, HW = hindwing, disp = dispersed, nondisp $=$ non-dispersed, $(*, \mathrm{P}<0.05 ; * *, \mathrm{P}<0.01 ; * * *, \mathrm{P}<0.001)$.

\begin{tabular}{|c|c|c|c|c|c|}
\hline Comparison & F-value & $\mathrm{p}$ & $\mathrm{D}$ & SE & $95 \%$ c.i. \\
\hline \multicolumn{6}{|l|}{ (A) } \\
\hline FW: & 118.93 & $\mathrm{p}<<0.0001^{* * *}$ & 0.0348 & 0.0015 & $0.0343-0.0421$ \\
\hline males vs females & $(4,1024)$ & & & & \\
\hline HW: & 23.40 & $\mathrm{p}<<0.0001 * * *$ & 0.0212 & 0.0019 & $0.0181-0.0253$ \\
\hline males vs females & $(6,1536)$ & & & & \\
\hline FW, females: & 3.01 & $0.0183^{*}$ & 0.0095 & 0.0033 & $0.0047-0.0178$ \\
\hline disp vs nondisp & $(4,456)$ & & & & \\
\hline HW, females: & 1.45 & 0.1942 & 0.0099 & 0.0045 & $0.0048-0.0224$ \\
\hline disp vs nondisp & $(6,684)$ & & & & \\
\hline FW, males: & 0.81 & 0.519 & 0.0046 & 0.0024 & $0.0022-0.0117$ \\
\hline disp vs nondisp & $(4,560)$ & & & & \\
\hline HW, males: & 0.43 & 0.858 & 0.0044 & 0.0021 & $0.0040-0.0121$ \\
\hline disp vs nondisp & $(6,840)$ & & & & \\
\hline \multicolumn{6}{|l|}{ (B) } \\
\hline FW: & 126.79 & $\mathrm{p}<<0.0001^{* * *}$ & 0.0347 & 0.0020 & $0.0309-0.0388$ \\
\hline males vs females & $(4,1024)$ & & & & \\
\hline HW: & 24.84 & $\mathrm{p}<<0.0001^{* * *}$ & 0.0212 & 0.0018 & $0.0181-0.0252$ \\
\hline males vs females & $(6,1536)$ & & & & \\
\hline FW, females: & 2.41 & $0.0486^{*}$ & 0.0082 & 0.0034 & $0.0037-0.0167$ \\
\hline disp vs nondisp & $(4,456)$ & & & & \\
\hline HW, females: & 1.23 & 0.286 & 0.0089 & 0.0045 & $0.0047-0.0220$ \\
\hline disp vs nondisp & $(6,684)$ & & & & \\
\hline FW, males: & 0.64 & 0.636 & 0.0041 & 0.0023 & $0.0020-0.0109$ \\
\hline disp vs nondisp & $(4,560)$ & & & & \\
\hline HW, males: & 0.59 & 0.739 & 0.0050 & 0.0019 & $0.0044-0.0120$ \\
\hline disp vs nondisp & $(6,840)$ & & & & \\
\hline
\end{tabular}

the variables that explained most of the variation in dispersal. However, applying the more sensitive test of comparing landmark positions between butterflies that did and did not disperse it was found that forewing shape of dis-

TABle 3. Logistic Regression Model for the migrant status of (a) each of the two sexes, and (b) the females. The explanatory variables used are release date, sex, forewing $(\mathrm{FW})$ aspect ratio, and shape asymmetry (measured as Procrustes distance between left and right wings).

\begin{tabular}{lrcc}
\hline Variable & coefficient & StDev & $\mathrm{p}$ \\
\hline (a) & & & \\
$\quad$ Constant & 2.899 & 1.864 & 0.120 \\
$\quad$ Release Date & -0.301 & 0.107 & 0.005 \\
$\quad$ Sex & 0.411 & 0.312 & 0.187 \\
(b) & & & \\
$\quad$ Constant & 8.879 & 3.701 & 0.016 \\
Release Date & -0.482 & 0.195 & 0.013 \\
FW aspect ratio & -0.164 & 0.132 & 0.213 \\
$\quad$ Shape asymmetry FW & 21.18 & 17.78 & 0.234 \\
\hline
\end{tabular}

persing females differed significantly from those that did not, with and without release date as a covariate (Table 2 ). The wings of dispersing females tended to be more rounded (see Fig. 2).

The shape of the hindwings of females that dispersed did, however, not differ from those that did not disperse. Although wing discs of both fore-and hindwing are supposed to be developmentally independent they interact with each other during development as they compete for the same resources (Nijhout \& Emlen, 1998), and often correlate in size and shape (Frankino et al., 2005). To investigate the morphological integration between foreand hindwings, we calculated the Pearson correlation between fore- and hindwing size (wing size: $\mathrm{R}=0.11, \mathrm{p}=$ $0.038)$ and the Escoufier vector correlation for shape $(\mathrm{R}=$ $0.030, p=0.012$ ) (for a mathematical description see Escoufier, 1973). These results indicate that although there is a high degree of integration between fore- and hindwing in $M$. cinxia, only the shape of the forewings covaried with dispersal, and only so in females. 


\section{DISCUSSION}

Male and female $M$. cinxia butterflies from Paldiski differed morphologically. Females were observed to have a significantly higher wing loading and wing aspect ratio than males. According to Betts and Wootton (1988), this would seem to indicate that females are capable of flying faster and more extensively than males. This is, however, a somewhat simplified view as studies on flight performance in butterflies have shown that flight speed and pattern also depend on factors such as thoracic mass (principally flight muscles), wing damage, centre of body mass, behavioral adaptations (e.g. predation avoidance), thermoregulation, wing asymmetry, and the ability to make use of spatial and temporal variation in the prevailing winds (Srygley \& Dudley, 1993; Dudley, 2000; Srygley \& Kingsolver, 2000; Srygley, 2001; Berwaerts \& Van Dyck, 2004; Berwaerts et al., 2006). It has recently been shown in $M$. cinxia that variation in the ability to disperse may be, amongst other things, caused by a variation in flight metabolic performance (measured as the [ATP] / [ADP] ratio of flight muscles following controlled activity). Rather interestingly, this can again only be established in dispersive females from newly established populations, and not in males (Hanski et al., 2004; Haag et al., 2005).

Sexual wing shape dimorphism is very common in butterflies and it is widely accepted that this dimorphism arises from the different ecological roles of flight between the sexes (Wickman, 1992; Van Dyck \& Wiklund, 2002; Berwaerts et al., 2006). The most striking result found in this study is that variation in forewing shape morphology is associated with dispersal in females only, not males, while both sexes did not differ in dispersal rates despite sexual wing shape dimorphism (cf. Wahlberg et al., 2002).

The present study and other relevant studies cited in this paper have merely described the existence of sexspecific differences in flight morphology, and related this to differences in life-history traits, or fitness components, associated with flight within each of the sexes. Differences in selection pressures were inferred. We know that male and female butterflies employ flight for different reasons and fly for different lengths of time, but how can we use this knowledge to understand the results in this and other studies found? To illustrate this with the most simple of all possible scenarios, let's imagine that a particular shape $\mathrm{Y}$ is optimal for dispersal, or searching for host plants and oviposition sites, while shape $\mathrm{X}$ is optimal for engaging in territorial disputes, with the shapes $\mathrm{X}$ and $\mathrm{Y}$ being very different. Males need to disperse and engage in male-male interactions (e.g. perching and patrolling), while females need to fly around in search of host plants. In this simple scenario, males experience two conflicting directional selection pressures on their wing shape. If both selection pressures are equal in magnitude the end result will effectively be a form of stabilizing selection. If not, then the stronger of the two will direct the wing shape to either $\mathrm{X}$ or $\mathrm{Y}$. Rather interestingly, a comparative study of 44 temperate butterfly species has shown that male body design is strongly affected by mating system, rather than dispersal (Wickman, 1992). Incidently, traits involved in sexual selection and/or under (conflicting) directional selection tend to be more weakly developmentally stabilized (Gangestad \& Thornhill, 1999; Breuker \& Brakefield, 2002). Males did indeed have significantly higher levels of wing shape FA (indicating low developmental stability of wing shape) than females in this study. This wing shape asymmetry was not in any way associated with dispersal, indicating that neither individual quality nor the shape asymmetry per se affect dispersal. This last result is perhaps not so surprising, given that not only does it appear quite common for insect forewings to show DA of wing size and shape, which may even be adaptive (Goulson et al., 1999; Windig \& Nylin, 1999), but free-flying insects often have asymmetric wing damage due to wing wear and failed predation attacks. Thus, insects appear to be highly capable of compensating for such asymmetries (reviewed in Dudley, 2000).

In the simple scenario outlined earlier, we would not expect wing shape to covary with dispersal in males, but we would in females, as found in this and other studies. We would furthermore expect females to have higher dispersal rates than males. Although this has generally been found in other studies, we did not find support for this in our study. A possible reason may be that males, given the experimental design of this study, had no choice but to follow the females if they were to obtain matings.

We could further elaborate this simple scenario by incorporating sex-specific responses to environmental factors (e.g. habitat fragmentation) and the possibility that selection pressures on wing shape may not only conflict simultaneously, but also sequentially, for example between seasons or in general between generations (Fric \& Konvička, 2002; Fric et al., 2006). Pararge aegeria butterflies, for example, are sexually dimorphic (e.g. White \& Winokur, 2003), and have sex-related adaptive seasonal plasticity for morphological traits related to flight (Van Dyck \& Wiklund, 2002). A study on $M$. cinxia on the Baltic island of Öland indicated that variation in overall body morphology was associated with variation in habitat fragmentation and dispersal, and that males and females have adapted differently to habitat fragmentation (Norberg \& Leimar, 2002).

Our study highlights the complexity of wing shape evolution. If one is ever to fully understand how factors like dispersal are associated with wing shape in butterflies we need actually to identify and quantify all the different selection pressures operating on wing shape.

ACKNOWLEDGEMENTS. We thank I. Hanski for making this study possible and for his support and insight throughout. We thank C.P. Klingenberg for his most helpful advice on the morphometric analyses and for his excellent comments on various drafts of the manuscript. Futhermore we would like to thank $\mathrm{Z}$. Fric, T. Merckx and an anonymous reviewer for many helpful comments in their review of this manuscript. The research was part of an EU-funded network called FRAGLAND. C.J. Breuker was funded by a NWO grant (33.360-P), and a Marie Curie Intra-European Fellowhip (MEIF-CT-2003-502052). 


\section{REFERENCES}

Baguette M. \& Neve G. 1994: Adult movements between populations in the specialist butterfly Proclossiana eunomia (Lepidoptera, Nymphalidae). Ecol. Entomol. 19: 1-5.

Baguette M., Convie I. \& Neve G. 1996: Male density affects female spatial behaviour in the butterfly Proclossiana eunomia. Acta Oecol. 17: 225-232.

Berwaerts K. \& VAN Dyck H. 2004: Take-off performance under optimal and suboptimal thermal conditions in the butterfly Pararge aegeria. Oecologia 141: 536-545.

Berwaerts K., Aerts P. \& Van Dyck H. 2006: On the sexspecific mechanisms of butterfly flight: flight performance relative to flight morphology, wing kinematics, and sex in Pararge aegeria. Biol. J. Linn. Soc. 89: 675-687.

BetTs C.R. \& Wootton R.J. 1988: Wing shape and flight behaviour in butterflies (Lepidoptera: papilionoidea and hesperioidea): a preliminary analysis. J. Exp. Biol. 138: 271-288.

BReuKer C.J. \& BRAKefield P.M. 2002: Female choice depends on size but not symmetry of dorsal eyespots in the butterfly Bicyclus anynana. Proc. R. Soc. Lond. 269: 1233-1239.

BReUKER C.J. \& BRAKefield P.M. 2003: Lack of response to selection for lower fluctuating asymmetry of mutant eyespots in the butterfly Bicyclus anynana. Heredity 91: 17-27.

BuCHANAN K.L. 2000: Stress and the evolution of conditiondependent signals. Trends Ecol. Evol. 15: 156-160.

Clarke G.M. 2003: Developmental stability - fitness relationships in animals: some theoretical considerations. In Polak M. (ed.): Developmental Instability: Causes and Consequences, Oxford University Press, New York, pp. 187-195.

Dryden I.L. \& Mardia K.V. 1998: Statistical Shape Analysis. Wiley, Chichester, $376 \mathrm{pp}$.

Dudley R. 2000: The Biomechanics of Insect Flight: Form, Function and Evolution. Princeton University Press, Princeton, New Jersey, $476 \mathrm{pp}$.

EhrLich P.R. \& HANSKI I. 2004: On the Wings of Checkerspots. A Model System for Population Biology. Oxford University Press, New York, 371 pp.

EsCOUfIER Y. 1973: Le traitement des variables vectorielles. Biometrics 29: 751-760.

Frankino W.A., Zwaan B.J., Stern D.L. \& Brakefield P.M. 2005: Natural selection and developmental constraints in the evolution of allometries. Science 307: 718-720.

Fric Z. \& KonvičKa M. 2002: Generations of the polyphenic butterfly Araschnia levana differ in body design. Evol. Ecol. Res. 4: 1017-1032.

Fric Z., Klímova M. \& KonvičKa M. 2006: Mechanical design indicates differences in mobility among butterfly generations. Evol. Ecol. Res. 8: 1511-1522.

GANGestad S.W. \& Thornhill R. 1999: Individual differences in developmental precision and fluctuating asymmetry: a model and its implications. J. Evol. Biol. 12: 402-416.

GibBs M. \& Breuker C.J. 2006: Effect of larval rearing density on adult life history traits and developmental stability of the dorsal eyespot pattern in the speckled wood butterfly Pararge aegeria. Entomol. Exp. Appl. 118: 41-47.

Gibis M., Lace L.A., Jones M.J. \& Moore A.J. 2004: Intraspecific competition in the speckled wood butterfly Pararge aegeria: effect of rearing density and gender on larval life history. $J$. Insect $S c i$. 4: 16, available online: insectscience.org/14.16.

Gibbs M., Lace L.A., Jones B.C. \& Moore A.J. 2005: Egg sizenumber trade-off and a decline in oviposition site choice quality: female Pararge aegeria butterflies pay a cost of having males present at oviposition. J. Insect Sci. 5: 39, available online: insectscience.org/35.39.
Goodall C.R. 1991: Procrustes methods in the statistical analysis of shape (with discussion). J. R. Stat. Soc. 53: 285-339.

Goulson D., Bristow L., Elderfield E., Brinklow K., Parry Jones B. \& Chapman J.W. 1999: Size, symmetry, and sexual selection in the housefly, Musca domestica. Evolution 53: 527-534.

HaAg C.R., SaAstamoinen M., Marden J.H. \& Hanski I. 2005: A candidate locus for variation in dispersal rate in a butterfly metapopulation. Proc. R. Soc. Lond. 272: 2449-2456.

HANSKI I. 1999: Habitat connectivity, habitat continuity, and metapopulations in dynamic landscapes. Oikos 87: 209-219.

HANSKI I. \& OVASKAINEN O. 2000: The metapopulation capacity of a fragmented landscape. Nature 404: 755-758.

Hanski I., Alho J. \& Moilanen A. 2000: Estimating the parameters of survival and migration of individuals in metapopulations. Ecology 81: 239-251.

Hanski I., Breuker C.J., Schöps K., Setchfield R. \& Nieminen M. 2002: Population history and life history influence the migration rate of female Glanville fritillary butterflies. Oikos 98: 87-97.

Hanski I., Eralahti C., Kankare M., Ovaskainen O. \& Siren H. 2004: Variation in migration propensity among individuals maintained by landscape structure. Ecol. Lett. 7: 958-966.

Hovorka M.D. \& RoberTson R.J. 2000: Food stress, nestling growth, and fluctuating asymmetry. Can. J. Zool. 78: 28-35.

Klingenberg C.P. \& MCInTyre G.S. 1998: Geometric morphometrics of developmental instability: Analyzing patterns of fluctuating asymmetry with procrustes methods. Evolution 52: 1363-1375.

Klingenberg C.P., Badyaev A.V., Sowry S.M. \& Beckwith N.J. 2001: Inferring developmental modularity from morphological integration: analysis of individual variation and asymmetry in bumblebee wings. Am. Nat. 157: 11-23.

KuUssaari M., Singer M. \& HANSKI I. 2000: Local specialization and landscape-level influence on host use in an herbivorous insect. Ecology 81: 2177-2187.

Mardia K.V., Bookstein F.L. \& Moreton I.J. 2000: Statistical assessment of bilateral symmetry of shapes. Biometrika 87: 285-300.

MARKOW T.A. 1995: Evolutionary ecology and developmental instability. Annu. Rev. Entomol. 40: 105-120.

MATESSI G. 1997: Is variation in orientation related to fluctuating asymmetry in migratory passerines? Ethol. Ecol. Evol. 9: 209-221.

Moller A.P. 1997: Developmental stability and fitness: A review. Am. Nat. 149: 916-932.

NiJHout H.F. \& EMLEN D.J. 1998: Competition among body parts in the development and evolution of insect morphology. Proc. Nat. Acad. Sci. U.S.A. 95: 3685-3689.

Norberg U. \& Leimar O. 2002: Spatial and temporal variation in flight morphology in the butterfly Melitaea cinxia (Lepidoptera: Nymphalidae). Biol. J. Linn. Soc. 77: 445-453.

NyLIN S. \& JANZ N. 1996: Host plant preferences in the comma butterfly (Polygonia c-album): Do parents and offspring agree? Ecoscience 3: 285-289.

Nylin S., Bergstrom A. \& Janz N. 2000: Butterfly host plant choice in the face of possible confusion. J. Insect Behav. 13: 469-482.

Palmer A.R. \& Strobeck C. 1986: Fluctuating asymmetry: measurement, analysis, patterns. Annu. Rev. Ecol. Syst. 17: 391-421.

Palmer A.R. \& Strobeck C. 2003: Fluctuating asymmetry analyses revisited. In Polak M. (ed.): Developmental Instabil- 
ity: Causes and Consequences. Oxford University Press, New York, pp. 279-319.

Rintamaki P.T., Ojanen M., Pakkala H. \& Tynjala M. 1995: Fluctuating asymmetry and autumn migration in willow warbler Phylloscopus trochilus L. Ornis Fenn. 72: 165-173.

Saccheri I., KuUssaari M., Kankare M., Vikman P., Fortelius W. \& HANSKI I. 1998: Inbreeding and extinction in a butterfly metapopulation. Nature 392: 491-494.

Singer M.C. \& HANSKi I. 2004: Dispersal behaviour and evolutionary metapopulation dynamics. In Ehrlich P.R. \& Hanski I. (eds): On the Wings of Checkerspots: A Model System for Population Biology, Oxford University Press, New York, pp. 181-198.

SRYgLey R.B. 2001: Compensation for fluctuations in crosswind drift without stationary landmarks in butterflies migrating over seas. Anim. Behav. 61: 191-203.

SRYGLey R.B. \& DudLey R. 1993: Correlations of the position of center of body mass with butterfly escape tactics. J. Exp. Biol. 174: $155-166$.

SRYgley R.B. \& KingSolver J.G. 2000: Effects of weight loading on flight performance and survival of palatable Neotropical Anartia fatima butterflies. Biol. J. Linn. Soc. 70 707-725.

SwaddLE J.P. 1997: Within-individual changes in developmental stability affect flight performance. Behav. Ecol. 8: 601-604.
Swaddle J.P. \& Witter M.S. 1994: Food, feathers and fluctuating asymmetries. Proc. R. Soc. Lond. 255: 147-152.

VAN DyCK H. \& WiKLUND C. 2002: Seasonal butterfly design: morphological plasticity among three developmental pathways relative to sex, flight and thermoregulation. J. Evol. Biol. 15: 216-225.

VAN Nouhuys S. \& HANSKI I. 1999: Host diet affects extinctions and colonizations in a parasitoid metapopulation. J. Anim. Ecol. 68: 1248-1258.

VAN VALEN L. 1962: A study of fluctuating asymmetry. Evolution 16: 125-142.

Wahlberg N., Klemetti T. \& Hanski I. 2002: Metapopulation structure and movments in five species of checkerspot butterflies. Oecologia 130: 33-43.

White R.J. \& WinOKUR L. 2003: Quantitative description and discrimination of butterfly wing patterns using moment invariant analysis. Bull. Entomol. Res. 93: 361-374.

WickMAn P.-O. 1992: Sexual selection and butterfly design - a comparative design. Evolution 46: 1525-1536.

Windig J.J. \& NYLIN S. 1999: Adaptive wing asymmetry in males of the speckled wood butterfly (Pararge aegeria)? Proc. R. Soc. Lond. 266: 1413-1418.

Zelditch M.L., Swiderski D.L., Sheets H.D. \& Fink W.L. 2004: Geometric Morphometrics for Biologists. Elsevier Academic Press, London, $443 \mathrm{pp}$.

Received December 28, 2006; revised and accepted February 28, 2007 